\title{
Analiza antropologiczna wczesnośredniowiecznej ludności z Milicza (XII-XIII w. n. e.)
}

\author{
Brunon Miszkiewicz, Stanislaw Gronkiewicz
}

ANTHROPOLOGICAL ANALYSIS OF EARLY MEDIEVAL POPULATION FROM MILICZ (12TH - 13TH c.). The investigated population originates from an area with a particularly intensive colonization. With the help of typological analysis the authors try to find ethnogenic connections of the population of Milicz.

Rozlegle cmentarzysko milickie zajmuje poludniowo-zachodnią część niezbyt wysokiego uprawnego wzniesienia, polożonego w dolinie Baryczy, po prawej stronie rzeki, ok. $500 \mathrm{~m}$ na pólnocny wschód od podmiejskich zabudowań Milicza. Znajduje się ono na wcześniejszych lużyckich i częściowo wczesnośredniowiecznych nawarstwieniach osadniczych. Cmentarzysko to przylega do grodziska datowanego na okres od $\mathrm{X}$ do XIII w. n. e.

Już $w$ polowie XIX w. stwierdzono istnienie w okolicach Milicza cmentarzyska rzędowego [GoTTSCHALK 1928]. Wedkug opisu, znaleziono wtedy $\mathrm{m}$. in.: kablączki skroniowe, miecze, noże itp. Materialy z ówczesnych badań nie zachowaly się jednak. Następne badania "sondażowe" podjęto dopiero po drugiej wojnie światowej. W roku 1953 pracownicy

Zaklad Antropologii PAN ul. Kuźnicza 35, 50-951 Wroclaw
Inspektoratu Ochrony Zabytków Archeologicznych we Wroclawiu wyeksplorowali kilka grobów szkieletowych i również zabytki: kablączki skroniowe, noże, szydla oraz ceramikę lużycką i wczesnośredniowieczną [GAŁUSZKO, MEYNARSKA 1957]. Systematyczne badania wykopaliskowe zostaly podjęte w 1960 r. z inicjatywy autora niniejszego opracowania (Zakład Antropologii PAN przy wspólpracy Konserwatora Zabytków Archeologicznych dra A. Galuszki). Badania te trwaly od 1960 do 1962 roku włącznie [MISZKIEWICZ 1961, 1962]. W tym czasie rozkopano ok. 18 arów i wyeksplorowano ok. 800 grobów szkieletowych (w tym skupiska kostne, luźne kości oraz groby fragmentaryczne).

Układ rzędowy cmentarzyska milickiego zostal częściowo zatarty poprzez dlugotrwale użytkowanie. Ogólna liczba pochowanych na nim osób mogla w 
rzeczywistości znacznie przekraczać 1000 . Glębokość zalegania szkieletów wahala się od 0,30 do $1,00 \mathrm{~m}$. Zmarli byli chowani, poza nielicznymi wyjątkami, w pozycji wyprostowanej, wzdluż osi wschód-zachód (glowę kierowano ku zachodowi), kończyny górne wyprostowane były wzdluż ciala, tylko w nielicznych przypadkach stwierdzono ulożenie jednej z rąk na miednicy; nie stwierdzono trumien, będacych w tym czasie w powszechnym użyciu. W 5 przypadkach zaobserwowano resztki konstrukcji kamiennych. Stanowi to niezwykle rzadkie zjawisko na cmentarzach śląskich tego okresu: znane sa jedynie z Lasocina (pow. Nowaı Sól), w Nowej Wsi Królewskiej (pow. Opole) i Niemczy (pow. Dzierżoniów).

Wyposażenie grobów było zależne od pici i wieku zmarlych (stwierdzono je w $28 \%$ grobów męskich, 50 żeńskich oriz21\% dziecięcych). Spośród przedmiotów kultury materialnej wchodzacych w sklad wyposażenia grobów można wymienić: 2 monety-brakteaty z XII w., noże metalowe, skórzane pochewki z brązowymi okuciami (również w grobach kobiecych), kablączki skroniowe $z$ esowatym uszkiem $z$ brązu platerowanego srebrem lub brązu posrebrzanego, pelne albo puste wewnątrz, pierścionki zamknięte lub otwarte. przeważnie $\mathrm{z}$ brąu, zdobione ornamentem rytym lub punktowym (liczne ze szkla, niekiedy z oczkiem szklanym lub plytką $z$ brązu), paciorki ze szkla przezroczystego (nieraz cale kolie z paciorków zdobionych) lub szklane zdobione, szlifowane. Ponadto znaleziono: kamienny rozcieracz, brązowy lańcuszek do zawieszenia oselki, kościane i żelazne igly, żelazne dlutka, rogowe rylce, odważniki z brazu itp. Brak zupelnie przedmiotów o znaczeniu sakralnym. Szczególował analizę archeologiczną materialu milickiego, $z$ uwzgle dnieniem analogii do znalezisk $\mathrm{z}$ terenów sajsiednich $\mathrm{z}$ tego okresu, przeprowadzil i opublikowal K. WACHOWSKI [1969, 1970, 1971].

Okres użytkowania cmentarzyska milickiego przypada na XII-XIII w.; nieliczne groby na krańcu poludniowym cmentarzyska mogą być nieco późniejsze, tj. do XIV w. Osada pod cmentarzyskiem przestala funkcjonować ok. XI-XII w. O upadku tej osady zdecydowaly warunki geograficzne oraz przemiany gospodarcze. Na lewym brzegu Baryczy powstaja w tym czasie liczne skupiska osadnicze. Cmentarz milicki byl do końca XIII w. miejscem chowania zmarlych dla ludności zamieszkującej pobliski gród i liczne osady, jak również dla mieszkańców "burgum" kasztelańskiego [MtYNARSKA 1960].

\section{Materiał i metoda}

Ogólny stan zachowania wyeksplorowanego materialu kostnego (ok. 800 osobników) jest średni, nieco lepiej zachowany jest material postkranialny, szczególnie zmarlych płci męskiej. Wyodrębniono ok. $15 \%$ szkieletów dziecięcych, $40 \%$ męskich oraz $45 \%$ żeńskich. Sredni wiek w chwili śmierci określono dla mężczyzn na maturus (środek), natomiast dla kobiet znacznie niższy - adultus (koniec).

Material kraniologiczny zmierzony zostal ogólnie przyjętą techniką R. Martina [MARTIN. Sal.l.er 1957]. Do szczególowej analizy statystycznej wyodrębniono material lepiej zachowany ( 245 mężczyzn i 155 kobiet). Obliczono charakterystyki statystyczne 115 cech kraniometrycznych (lącznie $z$ danymi z kraniogramów). osobno dla mężczyzn i kobiet.

Do typologicznej analizy indywidualnej metodą punktów odniesienia A. 
WANKEGO [1952, 1953, 1955], przy użyciu wypracowanych przez W. KóčKE [1958] stalych dla poszczególnych elementów antropologicznych (opracowanych i sprawdzonych na seriach od mezolitu do średniowiecza) uwzględniono wyłacznie najlepiej zachowane czaszki (185 męskich i 115 żeńskich). Dla czaszek żeńskich zastosowano poprawki w poszczególnych kategoriach wskaźników [KóČKA 1958].

\section{Wyniki}

Czaszki męskie jak i żeńskie scharakteryzować można następująco: są one dość duże, niezbyt masywne, dlugie i średniowysokie, $z$ silnie zaokraglona potylica. Twarz jest średnioszeroka i mezoortognatyczna, czolo jest średnioszerokie (nieco szersze u osobników męskich), również nos jest

Tabela 1. Niektóre dane statystyone cech pomiarowych czaszek męskich i żeńskich z Milicza ( $w \mathrm{~mm}$, pojemnosé $w \mathrm{~cm}^{3}$ )

\begin{tabular}{|c|c|c|c|c|c|c|c|c|c|c|}
\hline \multirow[t]{2}{*}{ Cecha } & \multirow[t]{2}{*}{$\boldsymbol{N}$} & \multicolumn{4}{|c|}{ Czaszki męskie } & \multirow[t]{2}{*}{$N$} & \multicolumn{4}{|c|}{ Czaszki żeńskie } \\
\hline & & & $s$ & $\min$ & - $\max$ & & $\bar{x}$ & $s$ & $\min$ & - $\max$ \\
\hline Pojemnose & 189 & 1447 & 138 & 1130 & - 1870 & 106 & 1340 & 128 & 1040 & -1680 \\
\hline Obwod & 245 & 521,6 & 16,3 & 470 & - 563 & 153 & 506,7 & 16,6 & 470 & 558 \\
\hline$g-o p$ & 242 & 186,8 & 6,9 & 167 & - 206 & 151 & 179,4 & 6,7 & 163 & 196 \\
\hline$b a \cdot b$ & 222 & 136,1 & 6,0 & 119 & 152 & 132 & 131,0 & 6,2 & 117 & 146 \\
\hline$e u-e u$ & 244 & 139,9 & 5,8 & 127 & 155 & 153 & 137,6 & 6,1 & 124 & 158 \\
\hline$f-f$ & 245 & 97,9 & 4,8 & 85 & 116 & 154 & 96,4 & 4,2 & 85 & 109 \\
\hline$z y-z y$ & 205 & 133,1 & 5,7 & 117 & 149 & 134 & 126,7 & 6,6 & 110 & 141 \\
\hline$z m-z m$ & 243 & 94,8 & 5,2 & 82 & 117 & 153 & 91,3 & 4,8 & 79 & 106 \\
\hline$a s t-a s t$ & 234 & 112,8 & 5,2 & 102 & 133 & 141 & 109,2 & 5,5 & 97 & 124 \\
\hline$m f-c k$ & 244 & 41,4 & 1,9 & 32 & 48 & 154 & 40,1 & 1,8 & 36 & 44 \\
\hline wysolose oczodolu & 245 & 32,2 & 2.1 & 25 & 38 & 154 & 32,2 & 1,9 & 27 & 37 \\
\hline$n-n s$ & 239 & 50,3 & 3,4 & 41 & 59 & 152 & 48,4 & 3,4 & 40 & 60 \\
\hline szer. otworu gruszk. & 239 & 24,7 & 1,9 & 19 & 31 & 152 & 24,1 & 1,6 & 20 & 28 \\
\hline$m \cdot p r$ & 217 & 69,1 & 4,7 & 57 & 81 & 135 & 66,1 & 4,7 & 55 & 81 \\
\hline kqt $n-p r / F H$ & 231 & $85,4^{\circ}$ & 3,80 & $73^{\circ}$ & 959 & 144 & 86,49 & 3,9 & $75^{\circ}$ & $96^{\circ}$ \\
\hline
\end{tabular}

Tabela 2. Srednie wskazników serii kraniologicznej z Milicza

\begin{tabular}{|c|c|c|c|c|c|c|c|}
\hline \multirow[t]{2}{*}{ Wskaźniki } & \multicolumn{2}{|c|}{ mężçyźni } & \multicolumn{2}{|c|}{ kobiety } & \multirow{2}{*}{$\begin{array}{c}\text { kobiety } \\
\text { z poprawką }\end{array}$} & \multicolumn{2}{|c|}{ mężczyźni + kobiety } \\
\hline & $n$ & $\bar{x}$ & $n$ & $\bar{x}$ & & $n$ & $\bar{x}$ \\
\hline szerokosciowo-dlugotciowy & 185 & 74,7 & 115 & 76,4 & 75,5 & 300 & 75,0 \\
\hline gómotwarzowy Kollmanna & 159 & 51,9 & 109 & 51,9 & 52,3 & 268 & 52,1 \\
\hline nosa & 184 & 49,0 & 115 & 49,8 & 48,8 & 299 & 48,8 \\
\hline aczodotów & 185 & 78,0 & 115 & 80,5 & 78,1 & 300 & 78,0 \\
\hline sklepieniowy Hrdlickj-Koxki & 172 & 83,2 & 100 & 82,7 & 83,2 & 272 & 83,2 \\
\hline
\end{tabular}


średnioszeroki, z wysoko wysklepionymi kośćmi nosowymi, a oczodoly są dość niskie (tab. 1, 2). Wysokość ciala jest średnia i wynosi dla mężczyzn $166,2 \mathrm{~cm}$, a dla kobiet 154,2 cm [GRALLA 1963, GRONKIEWICZ 1981].

Sklad antropologiczny dla obu plci odpowiada definicji typu pólnocno-zachodniego $z$ dużą przymieszką elementu laponoidalnego oraz archaicznego typu paleoeuropeidalnego $E A^{\prime P}$. Element armenoidalny nie odgrywa większej roli w tej populacji (tab. 3).

Tabela 3. Sklad rasowy serii kraniologicznej z Milicza

\begin{tabular}{|c|c|c|c|c|c|c|}
\hline \multirow[t]{2}{*}{ Plect } & \multicolumn{5}{|c|}{ elementy rasowe (w \%) } & \multirow[t]{2}{*}{ Struktura } \\
\hline & $a$ & $e$ & $h$ & $l$ & $p$ & \\
\hline Męska & 20,1 & 34,8 & 11,8 & 15,6 & 17,6 & $E A P I$ \\
\hline Zenska & 25,4 & 24,4 & 16,8 & 21,0 & 12,4 & $A E L$ \\
\hline Eącznie & 22,1 & 30,8 & 13,7 & 17,7 & 15,6 & $E A^{l} P$ \\
\hline
\end{tabular}

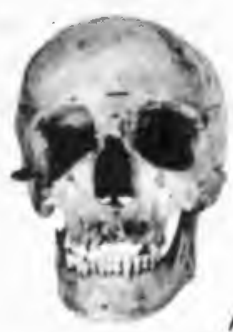

A
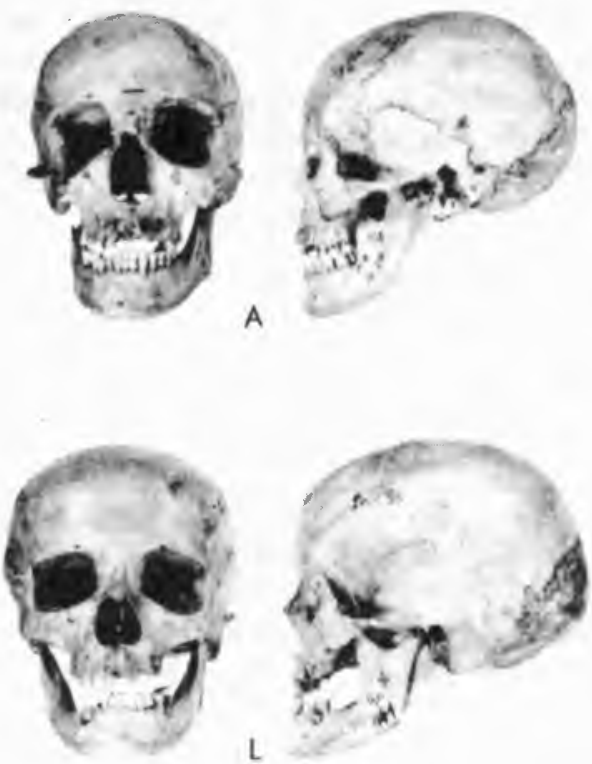

Zaobserwowano dość częste występowanie w znacznych odsetkach (przewaga) czterech typów antropologicznych $(A, E$, $L, P)$. Również w tym przypadku nie stwierdzono przewagi elementu armenoidalnego $(H)$. Niektóre charakterystyczne typy, odpowiadające ustalonym punktom odniesienia [KÓCKA 1958], przedstawia przykladowo tabela 4 oraz rysunek 1 .

Wykonano diagram różnic przeciętnych J. Czekanowskiego populacji milickiej na tle wczesnoslowiańskich serii $z$ tego samego okresu (rys. 2). Na podstawie średnich wartości wskaźników oraz skladów antropologicznych wydzielono w diagramie 3 grupy. Grupa I oraz II są najbardziej do siebie podobne i odpowiadają definicji typu pólnocno-zachodniego, $\mathrm{z}$ przewaga elementu śródziemnomorskiego wraz $\mathrm{z}$ nieznaczną domieszką składnika laponoidalnego. W grupie III znalazly się serie o charakterze sublaponoidalnym $\mathrm{z}$ silnymi
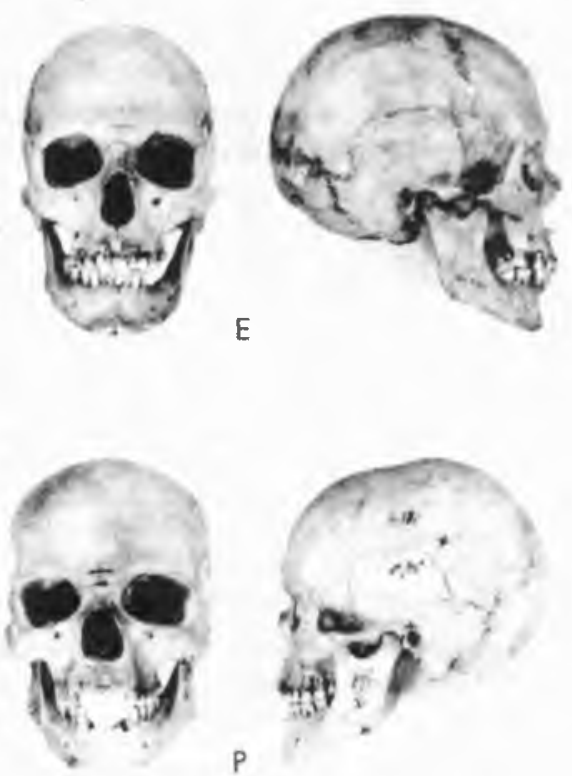

Rys. 1. Charakterystyczne caaszki odpowiadające definicjom typów antropologicanych, przedstawione w norma frontalis $i$ lateralis: A - typ nordyczny, E - śrdziemnomorski, L - Laponoidalny, P - paleoeuropeidalny 


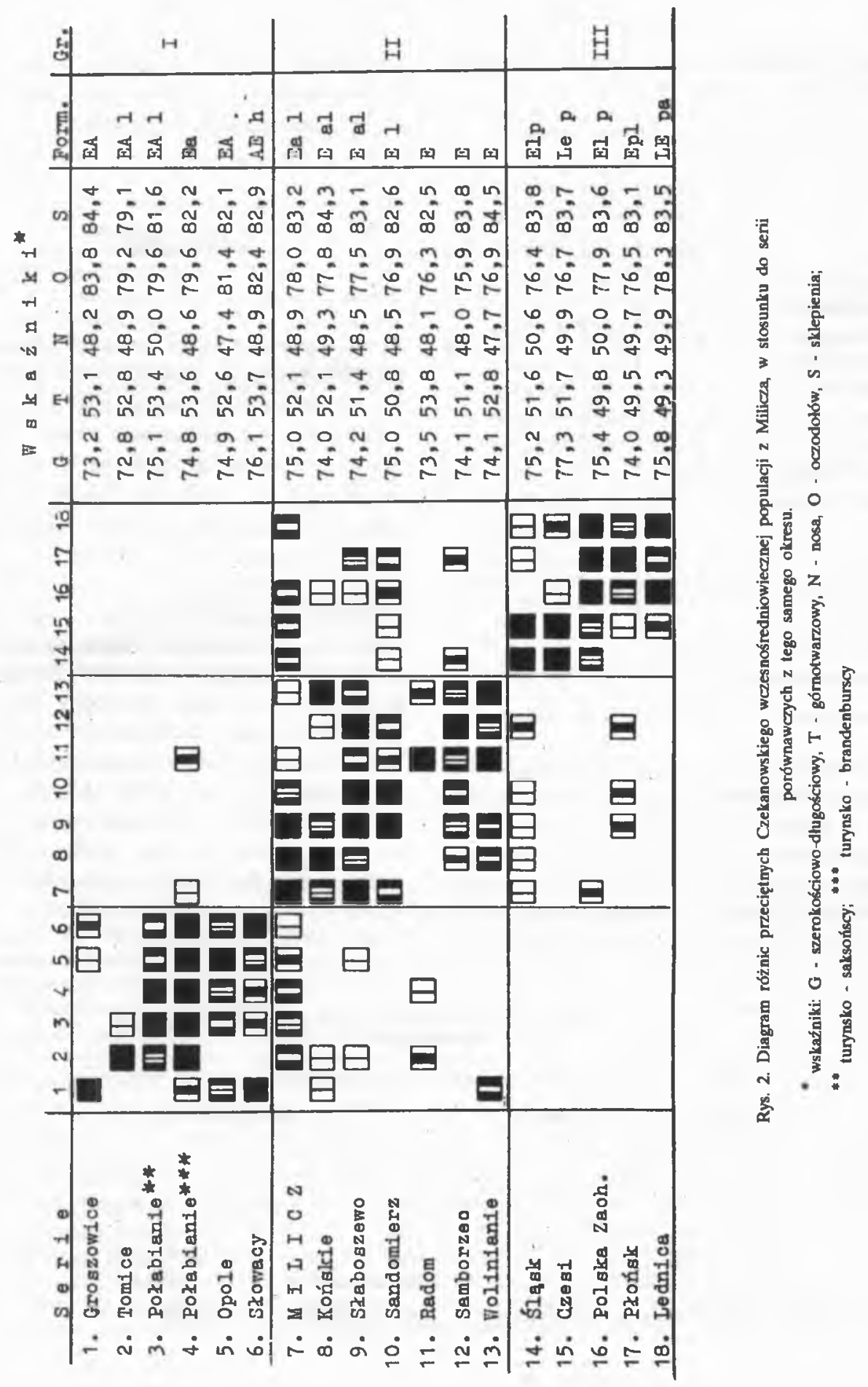


Tabela 4. Niektóre charakterystyczne typy antropologiczne z Milicza

\begin{tabular}{|c|c|c|c|c|}
\hline \multirow[t]{2}{*}{ Cecha } & \multicolumn{4}{|c|}{ Nr grobu } \\
\hline & $\begin{array}{l}105 \\
07\end{array}$ & $\begin{array}{r}16 \\
\sigma^{7}\end{array}$ & $\begin{array}{l}141 \\
q\end{array}$ & $\mid \begin{array}{c}246 \\
\sigma^{\prime \prime}\end{array}$ \\
\hline $\begin{array}{l}\text { Wskaźnik } \\
\text { szerokosciowo- }\end{array}$ & $\bar{x}$ & $\bar{x}$ & $\bar{x}$ & $\bar{x}$ \\
\hline $\begin{array}{l}\text {-dlugościowy } \\
\text { górnotwarzowy }\end{array}$ & 78,0 & 72,2 & 81,2 & 76,9 \\
\hline Kollmanna & 55,5 & 53,2 & 50,0 & 47,3 \\
\hline nosa & $\mathbf{4 0 , 7}$ & 42,0 & 54,2 & 53,3 \\
\hline $\begin{array}{l}\text { oczodolów } \\
\text { sklepieniowy }\end{array}$ & 88,4 & 79,5 & $\mathbf{7 4 , 4}$ & 67,5 \\
\hline (Hrdliそka-Kóčla) & 74,7 & 87,1 & 75,6 & wysoka \\
\hline typ & $\%$ & $\%$ & $\%$ & $\%$ \\
\hline Nardyczny (A) & 85,6 & 3,1 & 5,2 & 1,9 \\
\hline Śródziemnomorski (E) & 3,3 & 91,1 & 3,2 & 5,5 \\
\hline Armenoidalny $(\mathrm{H})$ & 8,2 & 2,6 & 4,1 & 2,1 \\
\hline Laponoidainy (L) & 1,9 & 1,4 & 82,5 & 19,2 \\
\hline Paleoeuropeidalny (P) & 0,9 & 1,3 & 5,2 & 71,6 \\
\hline
\end{tabular}

domieszkami skladnika paleoeuropeidalnego. Analizowana seria milicka znajduje się w grupie II, nawiązuje jednak swoimi wartościami (wskaźniki sklady, antropologiczne) silnie do grupy $I$, a slabiej do grupy III. Tabela 5 przedstawia orientacyjnie średnie cech grup wyróżnionych w diagramie. Dane te wskazują na duże podobieństwa pomiędzy poszczególnymi wczesnosłowiańskimi grupami.

\section{Wnioski}

W pobliżu olbrzymiego wczesnośredniowiecznego cmentarzyska milickiego, użytkowanego przez ponad dwa wieki, znajdowaly się wyjątkowo liczne osady. Korzystne warunki glebowe i dogodna lokalizacja w pradolinie rzeki Baryczy umożliwialy badanej ludności ciagly rozwój gospodarczy i powiększanie się populacji. Wyniki analizy antropologicznej serii z Milicza wskazują wyraźnie na północnozachodni, ze znacznym udzialem skladnika laponoidalnego, charakter antropologiczny tej populacji (jednolity dla obu plci). Populacja milicka należy niewątpliwie do formacji ludów slowiańskich Polski zachodniej [KOCKKA 1958, MISZKIEWICZ $1959,1957,1973]$. Potwierdzają to ponadto szczególowe analizy archeologiczne licznych przedmiotów kultury materialnej znalezionych w grobach [WACHOWSKI 1969, 1970, 1971].

Tabela 5. Srednie wskaznikow pokzczegolnych grup w diagramie oraz ich sktady antropologiczne

\begin{tabular}{l|c|c|c|c|c|c|c|c|c|c}
\hline \multirow{4}{*}{ Grupa } & \multicolumn{4}{|c|}{ Wakafniki* } & \multicolumn{4}{|c}{ Skbady antropologiczne [\%] } \\
& G & T & N & O & S & A & E & H & L & P \\
\hline I & 74,5 & 53,2 & 48,7 & 81,0 & 82,1 & 32 & 38 & 12 & 12 & 6 \\
II & 74,3 & 52,0 & 48,4 & 77,0 & 83,4 & 13 & 54 & 9 & 13 & 11 \\
III & 75,5 & 50,4 & 50,0 & 77,2 & 83,5 & 14 & 31 & 12 & 24 & 19 \\
\hline
\end{tabular}

- G - zzerokoiciowo-dhugosciony, T - ómotwarzowy, N - nose, O - aczodokbw, S - sklepienis, 


\section{Piśmiennictwo}

GALUSZKA A., M. MEYNARSKA, 1957, Sprawozdanie z prac wykopaliskowych w Miliczu, Wiadomości Archeologiczne, 24, 72.

GOTTSCHALK J., 1928, Der Hopfenberg bei Militsch ein slawischer Burgwall und zugleich Standort des Kastells Milissch, Heimat Jahrbuch, (Heimatblätter für den Kreis Militsch-Trachenberg, ar 2-5.

GRALLA G., 1963, Dhugosc in silu a werost wyliczony 2 kosci dhegich (Milicz), Mat. i Prace Antrop. 65, 241-268.

GRONKIEWICZ S., 1981, Analiza osteometryczna szkieletow 2 cmentarcysk przy kosciele fw. Piotra i Powla oraz przy kolegiacie NMP w Glogowie (XI-XIX w.), Przegl. Antrop., 47, 175-182.

KOCKA W., 1958, Zngadnienia etnogenezy ludów Eunopy, Mat. i Prace Antropol. 22

MARTIN R., K. SALLER, 1957, Lehrbuch der Anthropologie in systematischer Dassiellung, Stuttgart.

MISZKIEWICZ B., 1959, Cmentarzysko wczesnotredniowiecznew Groszowicach pod Opolem, Przegl. Antrop., 25, 221-230.

MISZKIEWICZ B., 1961, Sprawozdanie z prac wykopaliskowych kontynuowanych na cmentarzysku wezesnofredniowiecznym w Miliczu (woj. wroclawskie) wezasie ad 12 VI - 7 VIII 1961, Czlowiek w Cranie i Przestrzeni, r. IV, z. 3 (15), 123-124.

MISZKIEWICZ B., 1962, Sprowozdanie z prac wykopaliskowych prowadzonych w 1962 r. na cmentarzysku wczesnotredniowiecznym w miejscowości Milicz, Człowiek w Czasie i Przestrzeni, r. V, z. 3 (19), 121 122.

MISZKIEWICZ B., 1967, Ludnost Sredniowieczna Opola w swietle badari antropologicznych, Mat. i Prace Antrop., 74, 199-216.

MISZKIEWICZ B., 1973, Ludnosć wczesnostredniowieczna $z$ Tomic $w$ twietle danych antropologicznych, [w:] Tomice, pow. Dziertoniow, wielokulunowe stanowisko archeologicene, Wrochaw, 261-296.

MKYNARSKA M., 1960, Bungum milickie, Kwart. Hist. Kult. Mat., 8, 453-457.

WACHOWSKI K. 1969, 1970, 1971, WczesnoIredriowieczne cmentarzysko szkieletowe w Miliczu, Silesia Antiqua, 11, 199-223; 12, 123-187; 13, 191-213.

WANKE A., 1952, Czestosté zespolów cech antropologicznych, Prace Wrocl. Tow. Nauk, 29, 5-57.

WANKE A., 1953, New taxonomic method in anthropology and its application, Bull de l'Acad. Pol. Sc., cl. II, 1922.

WANKE A., 1955, Indywidualne okreflanie taksonomiczne, Przegl. Antrop., 21, 968-990.

Maszynopis nadeslano w styezniu 1986 r.

\section{Z u s a m e n a s u n $\mathrm{g}$}

ANTROPOLOGISCHE ANALYŠ DER FRÜHMITTELALTERLICHEN BEVÖLKERUNG AUS MILICZ (XII-XIII JHT. U. ZT.). In den Jahren 1960-1962 fuhrte die Abteilung Anthropologie der Polnischen Akademie der Wissenschaften und der Konservator von archäologischen Denkmälern in Wroclaw systematische Forschungen, Ausgrabungen (teilweise auf $18 \mathrm{Ar}$ ) in Milicz aus (Niederschlesien). Das grosse Reihengräberfeld befindet sich auf frühlausizzer und teils X/XI Jht. frühmittelalterlichen Siedlungsresten, in nächster Nachbarschaft eines Burgwalls. Die Chronologie des Gräberfelds konnte zwischen dem XII. bis XIII. Jht. festgestellt werden (darunter Fragmentskelettgräber und reichliche Knochenanhäufungen). Die Gräber waren mit folgenden Beigaben ausgestattet, wie: 2 Münzen (Brakteate aus dem XII Jht.), zahlreiche Schläfenringe, Messer, Messerscheidenbeschläge, Glasperlen, Fingerringe, Bronzeketten, KnochenEisennadeln, Spinnwirtel, Hornstichel, Keramik usw. Eine eingehende archäologische Analyse, mit Fundanalogien, wurde von dr. K. Wachowski durchgeführt und dementsprechend publiziert.

Das Skelettmaterial wurde anthropologisch analysiert. Der Erhaltungszustand des explorierten Skelettmaterials ist măssig bis schwach. Es konnten $15 \%$ Kindergräber, $40 \%$ Männer - und $45 \%$ Frauengräber ausgesondert, festgestellt werden. Das mittlere Alter beträgt bei Männerserien Maturus, bei der Frauenserie Adultus (wesentlich niedriger).

Insgesamt wurden 245 Männer - und 155 Frauenkranien statistisch analysiert (115 kraniometrische Merkmale). Zur individuellen Typenanalyse nach dem Approximationsverfahren von A. WANKE, und den bearbeiteten anthropologischen Konstanten von W. Kócka, wurden 185 Männer - und 155 Frauenschädel berücksichtigt (ausschliesslich komplete Kranien). Die anthropologische Analyse sowohl männlicher, wie auch 
weiblicher Kranien brachte folgende Ergebnisse: die Schädel sind lang und mittelhoch, das Gesicht und die Nase ist mittelbreit mit niedrigen Orbitae. Die typologische Zusammensetzung entspricht einer nord-westFormation (Definition) mit starken lapponoiden und paläoeuropiden Beimischungen (Tabellen 1-5). Ausserdem wurde, nach J. Czekanowski, ein Diagramm von 17 slavischen Vergleichsserien aufgestellt (Abb.2). Beispielshalber wurden auch 4 charakteristische anthropologische Typen angeführt (Tab. 4, Abb, 1). Die armenoide Beimischung spielt in dieser Population keine wesentliche Rolle.

Anhand der anthropologisch-archäologischen Analyse (Ergebnisse) ist die frühmittelalterliche Population aus Milicz eine typisch slavische Formation West-Polens. 